\title{
A visão através dos contrastes
}

\author{
GIVAGO DA SILVA SOUZA, ELIZA MARIA DA COSTA BRITO \\ LACERDA, VLADÍMIR DE AQUINO SILVEIRA, CAROLINA \\ DOS SANTOS ARAÚJO e LUIZ CARLOS DE LIMA SILVEIRA
}

\section{O processamento visual de contrastes}

A

S RADIAÇÕES eletromagnéticas dentro da faixa de comprimentos de ondas entre aproximadamente $380 \mathrm{~nm}$ e $760 \mathrm{~nm}$ vindas do ambiente en-

tram em contato com fotorreceptores na retina e podem ser convertidas em sinais eletroquímicos (Luo, 1999). Esses sinais são transmitidos e codificados através de redes neuronais que levam, entre outros efeitos, à geração da percepção visual consciente. Desde a recepção da energia eletromagnética até a geração da percepção consciente, ocorrem diversos processos de codificação da informação cuja compreensão é fundamental para entender-se como a visão funciona. Os processos mais distais são mais bem entendidos, enquanto aqueles que ocorrem progressivamente mais centralmente são da mesma forma progressivamente menos entendidos.

Nos fotorreceptores, a codificação da informação luminosa ocorre através da transdução da quantidade de fótons absorvidos pelos fotopigmentos em amplitudes de alterações graduadas do potencial de membrana da célula fotorreceptora (Lamb; Pugh Jr., 1992; 2006). As respostas elétricas dos fotorreceptores aos estímulos luminosos são hiperpolarizantes (Naka; Rushton, 1966). Em síntese, os fotorreceptores funcionam como contadores dos fótons absorvidos, em outras palavras, do número de eventos de absorção de fótons pelos fotopigmentos que levam a fotoisomerizações desses fotopigmentos e ativação da cascata de fototransdução (Lamb; Pugh Jr., 1992; Yau, 1994).

A partir da próxima etapa do processamento visual, a sinapse entre fotorreceptores e células bipolares, inicia-se uma transformação da informação luminosa. As células bipolares comparam as informações oriundas de diferentes fotorreceptores, fazendo surgir pela primeira vez dentro do processamento visual a informação de contraste (Werblin; Dowling, 1969; Zhang; Wu, 2009). As células bipolares fazem a codificação de contraste graças à organização de seus campos receptivos com diferentes propriedades de ativação / inibição entre as áreas centrais e periféricas desses campos. A estrutura do campo receptivo com antagonismo funcional entre seu centro e periferia é o circuito básico para o processamento da informação espacial no sistema visual. A geração da oponência entre centro e periferia dos campos receptivos das células bipolares tem origem em acoplamentos entre células bipolares e na combinação de várias vias sinápticas mediadas por células horizontais e amácrinas (para maiores detalhes 
desses circuitos neurais, ver Zhang; Wu [2009]). Graças a diferentes receptores de glutamato nas sinapses com os fotorreceptores, em resposta à estimulação luminosa as células bipolares podem sofrer despolarização, sendo chamadas de células "on" as quais usam receptores metabotrópicos de glutamato, ou hiperpolarização, sendo chamadas de células "off” e que usam receptores ionotrópicos de glutamato (Nawy; Jahr, 1990; 1991; DeVries; Schwartz, 1999). Além disso, as células bipolares usam diferentes subtipos de receptores de glutamato ionotrópicos ou metabotrópicos para filtrar a informação visual temporal em canais separados (DeVries, 2000). As taxas de recuperação desses receptores de glutamato após sua estimulação por esse neurotransmissor e sua dessensibilização define as características sustentadas (tônicas) ou transitórias (fásicas) das respostas das diferentes células bipolares, de tal forma que o processamento temporal da informação visual começa também nas primeiras sinapses do sistema visual, tal como o processamento espacial e a divisão do processamento visual em vias on e off (DeVries, 2000).

As células bipolares fazem sinapse com as células ganglionares na região interna da retina (Masland, 2001). As células ganglionares também têm um campo receptivo do tipo centro-periferia com características antagônicas (Kuffler, 1953; Barlow et al., 1964). O contato com diferentes tipos de bipolares (on ou off) e a modulação direta ou indireta de interneurônios (células amácrinas e células horizontais) leva ao antagonismo centro-periferia dos campos receptivos dessas células (Mangel; Miller, 1987; Croner; Kaplan, 1995). As células ganglionares podem ser divididas em três grandes classes neuronais: as células $\mathrm{P}$ que correspondem aproximadamente a $80 \%$ das células ganglionares da retina; as células $\mathrm{M}$ que correspondem aproximadamente a $10 \%$ das células ganglionares da retina e as células K que correspondem às demais (Perry et al., 1984; Silveira; Perry, 1991; Dacey et al., 2003; Dacey; Packer, 2003). As células P e $\mathrm{M}$ apresentam homogeneidade estrutural e funcional dentro de cada classe nas diferentes localizações retinianas (Lee et al., 1989a,b,c). O grupo de células Ké formado por células de diferentes morfologias e fisiologias e têm sido estudadas em menor profundidade que as células M e P (Dacey et al., 2003; Dacey; Packer, 2003; Szmajda et al., 2008).

$\mathrm{Na}$ camada de células ganglionares, além da continuação da codificação do contraste espacial e temporal, inicia-se a codificação das três dimensões de cores de contraste. As células $\mathrm{M}$ e $\mathrm{P}$ podem receber informação somada dos cones $\mathrm{L}$ e $\mathrm{M}$ tanto na periferia como no centro de seu campo receptivo. Assim, a comparação dessas informações indica a diferença de intensidades luminosas entre duas áreas vizinhas, representando o substrato inicial da percepção de contrastes de luminância ou canal de oponência preto e branca (Lee et al., 1989a,c). As células $\mathrm{P}$ também podem receber informações exclusivas vindas de cones $\mathrm{L}$ ou $\mathrm{M}$ no centro e periferia dos seus campos receptivos. Esse tipo de campo receptivo compara os sinais de longos e médios comprimentos de ondas e representa 
o substrato inicial da percepção de contraste de cor verde-vermelho ou canal de oponência verde-vermelha (Lee et al., 1989a). Uma subclasse específica de célula $\mathrm{K}$, as células pequenas biestratificadas, recebem informações vindas de cones $S$ de natureza excitatória e informações oriundas de cones L e M de natureza inibitória (Dacey; Lee, 1994). Essas células comparam os sinais de comprimento de ondas curto com os sinais somados de comprimentos de ondas médios e longos. Esse processamento representa o início da percepção de contraste de cor azul-amarelo ou canal de oponência azul-amarela.

As informações desses três sinais de saída da retina é enviada para diferentes camadas do núcleo geniculado lateral do tálamo cursando pois de forma paralela e sem haver mistura entre elas (Perry et al., 1984; Szmajda et al., 2008). As células talâmicas mantêm as propriedades fisiológicas de suas correlatas na camada de células ganglionares da retina (Irvin et al., 1993). As informações do tálamo são enviadas para o córtex visual primário. Até a chegada ao córtex visual primário as informações dos canais de oponência mantêm-se segregadas, mas já nas primeiras sinapses corticais estas informações são combinadas (Hendrickson et al., 1978; Blasdel; Lund, 1983; Lachica et al., 1992; Yabuta; Callaway, 1998; Chatterjee; Callaway, 2003). Após o córtex visual primário, a informação visual é transmitida para outras áreas corticais, constituindo duas grandes vias, uma ventral e outra dorsal no córtex cerebral (Ungerleider; Mishkin, 1982; Van Essen et al., 1992). Em geral, a estrutura de campo receptivo ao longo das áreas corticais visuais torna-se mais complexa quanto maior é o nível de hierárquico do processamento cortical.

\section{O papel do contraste na visão}

Um objeto só consegue ser identificado caso haja contraste entre ele e o ambiente ao seu redor. Regan (2000) indica que há pelo menos cinco tipos diferentes de contraste que podem diferir um alvo do fundo sobre o qual ele é observado. Esses contrastes são: contraste espacial de luminância, representado pela diferença de intensidades luminosas no domínio do espaço entre o alvo e o fundo; contraste espacial de cor representada pela diferença de conteúdo espectral entre o alvo e o fundo; o contraste de texturas representado pelas diferentes características de linhas que compõem o alvo e fundo; contraste temporal de luminância ou crominância; e contraste de disparidade ocular, que é a diferença de posicionamento da imagem sobre os dois olhos. Esse é o princípio da camuflagem natural: quanto mais propriedades o alvo compartilhar com o fundo, mais difícil será para um observador distinguir os elementos de uma cena visual.

Uma aplicação desses conhecimentos, mesmo que de forma intuitiva, é a técnica de ilusionismo chamada de "Black art", da qual um dos principais expoentes é o mágico francês Omar Pasha. Na "Black art", o ilusionista busca fazer coisas aparecerem e desaparecerem apenas com o ato de cobrir ou descobrir objetos com tecidos que apresentam baixíssimo contraste com o fundo. Outro exemplo da mesma aplicação e que apresenta beleza comparável é em teatro 
de bonecos, no qual os artistas ficam vestidos com roupas normalmente bem escuras contra um fundo escuro manipulando as ações das marionetes. Rapidamente deixamos de perceber a presença das mãos manipuladoras e os bonecos parecem ter vida. Há vários endereços na internet que mostram a arte de nos enganar pela diminuição do contraste (por exemplo, http://www.youtube.com/ watch?v=S1Mmdilevo4).

\section{O estudo da sensibilidade ao contraste e o significado da função de sensibilidade ao contraste}

Este artigo buscará restringir-se à percepção de contraste espacial de luminância, a função visual que nos proporcionaria um mundo em branco-e-preto não fôssemos dotados igualmente da capacidade de distinguir os contrastes de crominância verde-vermelho e azul-amarelo. A combinação dessas três formas de contrastes nos proporciona a visão de cores - branca, preta, verde, vermelha, azul, amarela e suas combinações.

O ambiente não é uniformemente iluminado nem reflete a mesma composição espectral nos diferentes pontos do espaço. Assim as imagens naturais apresentam uma mescla de cores com diferentes intensidades luminosas ao longo do domínio espacial. Como dito anteriormente, as células ganglionares retinianas separam as informações de contrastes de luminância (células $\mathrm{M}$ e P) das informações de contraste de cores (células P e K). Assim é comum que em experimentos científicos sejam utilizados estímulos que isolam as informações de luminância ou de cor com o intuito de estudar separadamente os processamentos realizados por essas diferentes classes celulares (por exemplo: Dacey; Lee, 1994; Silveira et al., 1999; Lee et al., 2000).

No estudo da visão espacial os contrastes são determinados pela diferença de luminância entre regiões contíguas do estímulo, ou seja, ao longo da dimensão espaço. A Figura 1A mostra uma sequência de quadrados brancos contra um fundo preto. Cada quadrado tem um tamanho específico que corresponde a meio período espacial. A partir do período pode ser calculada a frequência espacial correspondente. Com efeito, funções definidas na dimensão espaço podem ser convertidas em funções definidas na dimensão frequência espacial, usando-se a transformada Fourier - os domínios do espaço e das frequências espaciais são domínios correlatos. Na Figura 1B são mostrados os estímulos cujas frequências espaciais seriam equivalentes à dimensão espacial dos quadrados da Figura 1A.

Uma questão primordial que surgiu nos estudos da percepção visual foi como o sistema nervoso respondia para estímulos contrastantes no domínio do espaço ou das frequências espaciais. Uma abordagem muito empregada no estudo do processamento do contraste do sistema visual é a estimativa do limiar de detecção do contraste. O contraste é compreendido como um domínio que representa a magnitude do estímulo e é apresentado ao sistema visual em diferentes faixas desse domínio. O objetivo desse tipo de experimento é identificar o contraste em que a probabilidade de detecção do estímulo é equivalentes à 
probabilidade de não detectá-lo. O contraste limiar é o menor contraste que gera a resposta do sistema visual, mas ele não representa um valor fixo e sim um valor probabilístico. É comum no estudo de sistemas sensoriais converterem-se os valores de limiar em valores de sensibilidade. Uma forma de fazer isso é achar a função inversa do contraste limiar para representar a sensibilidade ao contraste.

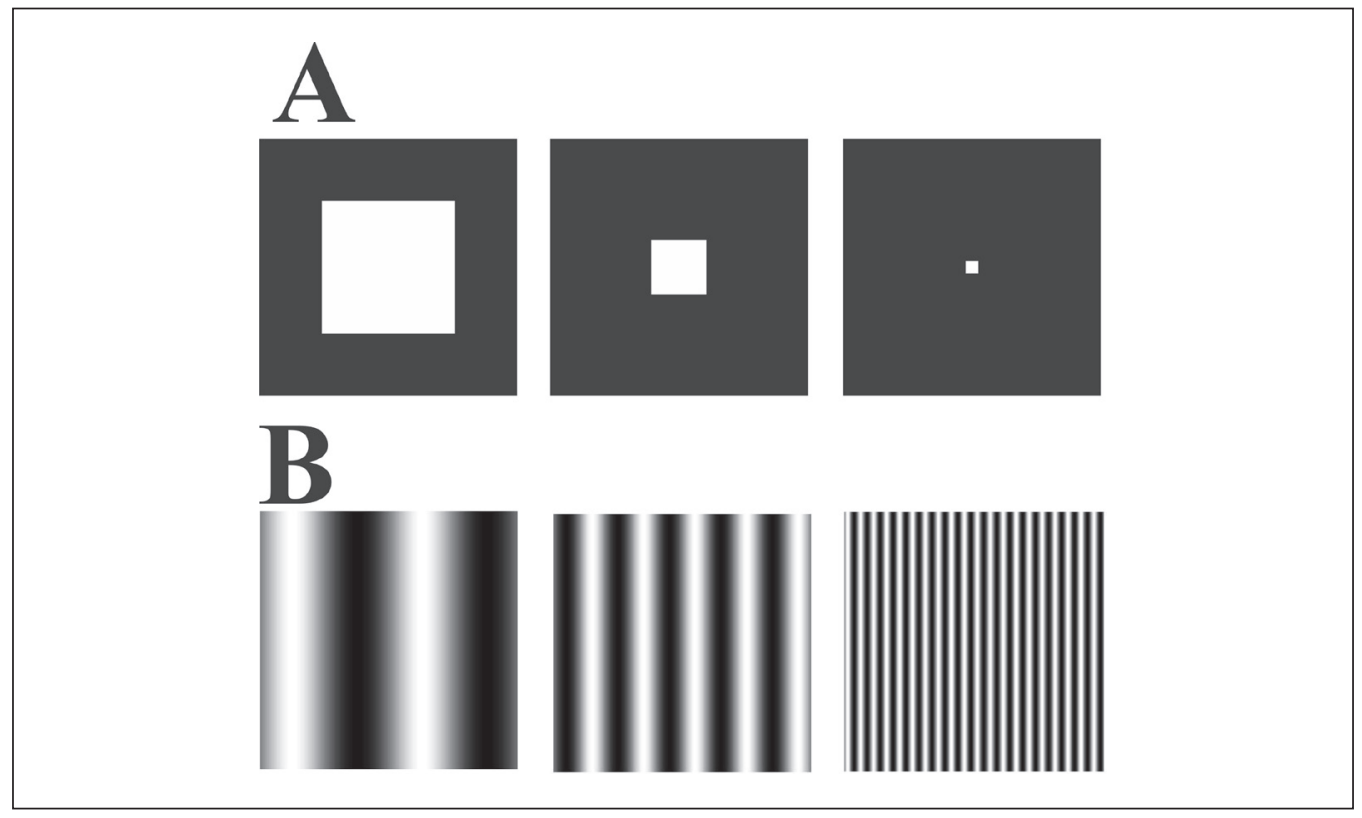

Figura l - Representações do contraste no domínio do espaço (A) e no domínio das frequências espaciais (B). As dimensões dos quadrados são equivalentes às frequências espaciais das faixas imediatamente abaixo.

Assim, os primeiros experimentos para testar a sensibilidade do sistema visual humano aos contrastes espaciais foram aqueles utilizando métodos psicofísicos nos quais eram mostrados estímulos de contraste espacial de luminância com diferentes frequências espaciais (Schade, 1956; Campbell; Green, 1965). Os resultados mostraram uma função em forma de sino. Havia uma faixa de frequências espaciais (ou tamanhos) que era mais bem identificada pelo sistema visual e que tanto para valores maiores e menores a sensibilidade diminuía. Essa função ficou conhecida como função de sensibilidade ao contraste espacial de luminância. Essa função separa o mundo dos contrastes visíveis e invisíveis do sistema visual humano (Figura 2). Ela é uma das funções de transferência que caracteriza o sistema visual, tal como uma função de transferência óptica caracteriza a capacidade de uma lente, um conjunto de lentes ou qualquer equipamento óptico reproduzir no meio imagem as frequências espaciais presentes no meio objeto. Procedimentos equivalentes são usados em acústica e eletricidade para estudar a capacidade de um equipamento sonoro ou eletroeletrônico reproduzir em sua saída o sinal de entrada. 
A função de sensibilidade ao contraste pode ser afetada por dificuldades na geração de estímulos com o contraste espacial desejado, pelas características da óptica ocular, pela biofísica da fototransdução e pelo funcionamento dos neurônios da via visual.

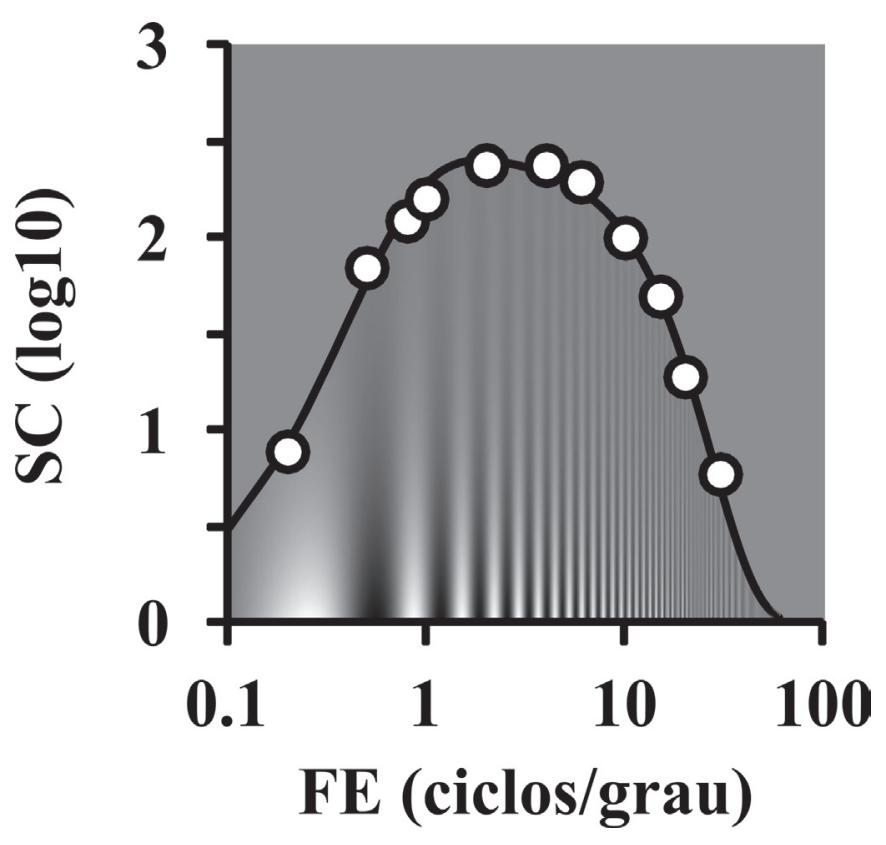

Figura 2 - Sensibilidade ao contraste espacial de luminância em função das frequências espaciais. A sensibilidade ao contraste pode ser estimada em diferentes frequências espaciais (círculos) e depois pode a ela ser ajustada uma função com forma de sino. A curva ou função de sensibilidade ao contraste espacial de luminância separa o mundo do visível (abaixo da curva) do mundo do invisível (acima da curva). A diminuição da sensibilidade ao contraste em frequências espaciais altas é devida a fatores ligados à transmissão de contrastes pela óptica do olho, enquanto a atenuação nas frequências espaciais baixas é devida a fatores neurais como a organização dos campos receptivos dos neurônios visuais em regiões centrais e periféricas antagônicas.

Posteriormente foram desenvolvidos estimuladores capazes de mostrar adequadamente os contrastes em uma grande faixa do espectro das frequências espaciais, de tal forma a não influenciar o formato da função resposta do sistema visual, e foi demonstrado que a óptica do olho como qualquer outro sistema óptico distorce a informação de contraste principalmente nas frequências espaciais mais altas (Campbell; Green, 1965; Campbell; Gubisch, 1966). Assim, o formato da função de sensibilidade ao contraste espacial de luminância parece ser influenciado por fatores ópticos, já que a informação é alterada antes de chegar aos neurônios, e por fatores neurais, já que o formato da função final não 
representa a função de entrada enviada pelo sistema óptico para o sistema neural (Campbell; Green, 1965; Campbell; Gubisch, 1966).

A função de sensibilidade ao contraste espacial de luminância tem sido extensivamente estudada por diferentes métodos, incluindo diversos métodos psicofísicos e eletrofisiológicos (Campbell; Kulikowski, 1966; 1971; 1972; Campbell; Robson, 1968; Blakemore; Campbell, 1969a,b; Blakemore et al., 1970; Campbell; Maffei, 1970; Souza et al., 2007) e em diferentes espécies (revisto em: Souza et al., 2011) ao longo das últimas cinco décadas. Vale destacar aqui um conjunto de experimentos psicofísicos no qual a adaptação para estímulos de alto contraste e uma determinada frequência espacial produzia uma diminuição da sensibilidade ao contraste para um conjunto de frequências espaciais centradas na frequência espacial do estímulo de adaptação (Pantle; Sekuler, 1968; Gilinsky, 1968; Blakemore; Campbell, 1969). A largura da banda de frequências espaciais que poderia ser influenciada pela frequência espacial de adaptação era próxima a uma oitava. Esse efeito foi observado na faixa de frequências espaciais de 3 a 14 cpg. Para frequências de adaptação menores que 3 cpg, o pico do efeito manteve-se próximo a $3 \mathrm{cpg}$. Isso sugeriu que o sistema visual tem neurônios seletivos a faixas de frequências espaciais, e por ser específico à orientação e apresentar transferência interocular foi sugerido que esse efeito tinha origem cortical (Gilinsky, 1968; Blakemore; Campbell, 1969). Assim, ao usar várias frequências espaciais no estímulo de adaptação, é possível encontrar as funções de sensibilidade ao contraste dos diferentes subsistemas de análise das frequências espaciais que compõem a função de sensibilidade ao contraste. Há uma série de argumentos sugerindo que esses subsistemas (ou canais de frequências espaciais) são independentes entre si: o valor do contraste limiar de estímulos de luminância modulados por determinadas funções complexas é determinado unicamente pelo componente senoidal fundamental da função e estímulos com a mesma frequência espacial e com modulação de luminância que obedecem a funções senoidais e quadradas são indistinguíveis no nível limiar (Campbel; Robson, 1968). Os canais seletivos às frequências espaciais parecem ser a base do processamento inicial de imagens complexas.

\section{$O$ papel das vias $M$ e $P$}

\section{na função de sensibilidade ao contraste espacial de luminância}

Uma linha importante de estudo sobre as bases fisiológicas da função de sensibilidade ao contraste espacial de luminância é a investigação do papel das vias visuais $\mathrm{M}$ e $\mathrm{P}$ em sua geração. Nos laboratórios na Universidade Federal do Pará (Laboratório de Neurofisiologia Eduardo Oswaldo Cruz e Laboratório de Neurologia Tropical) temos investigado esse questionamento mediante métodos não invasivos em humanos. Souza et al. (2007) estudaram a sensibilidade ao contraste espacial de luminância pelo registro do potencial cortical provocado visual (detalhes da técnica: Odom et al., 2004) gerado por estímulos de diferentes frequências espaciais e contrastes. Eles observaram que a amplitude 
do potencial cortical provocado visual em função do contraste era influenciada pela frequência espacial do estímulo. Em frequências espaciais baixas $(0,4 \mathrm{cpg})$ a função estimada mostrava um aumento linear da amplitude do sinal em função do logaritmo do contraste para valores baixos de contrastes e saturação em altos contrastes. Em frequências espaciais intermediárias a altas havia uma dupla tendência no aumento da amplitude do sinal em função do logaritmo do contraste. A explicação para os tais achados foi buscada nos dados obtidos em registros eletrofisiológicos de células ganglionares de primatas não humanos. Kaplan e Shapley (1986) encontraram que as células ganglionares $M$ respondiam linearmente em baixos contrastes e com forte saturação da resposta em contrastes médios a altos, enquanto as células ganglionares $\mathrm{P}$ aumentavam linearmente sua taxa de disparos em uma maior gama de contrastes. A principal conclusão desse estudo foi que as células ganglionares $\mathrm{M}$ e células ganglionares $\mathrm{P}$ representavam sistemas de alta sensibilidade ao contraste (via $\mathrm{M}$ ) e de baixa sensibilidade ao contraste (via P). Assim, a sugestão de Souza et al. (2007) foi de que em frequências espaciais mais baixas em todos os contrastes a via $\mathrm{M}$ é a principal geradora das respostas corticais provocadas, enquanto nas frequências espaciais médias e altas, os registros obtidos em altos contrastes seriam gerados pela atividade somada das vias $\mathrm{M}$ e $\mathrm{P}$, enquanto em contrastes mais baixos apenas as células da via $M$ estariam contribuindo para a resposta visual. Essa sugestão é compartilhada com outros estudos de diferentes grupos (Nakayama; Mackeben, 1982; Valberg; Rudvin, 1997; Rudvin et al., 2000; Souza et al., 2008; 2012). Assim, como a função de sensibilidade ao contraste é estimada no nível limiar, a via $\mathrm{M}$ seria responsável pelos valores de sensibilidade ao contraste pelo menos na faixa de frequências espaciais entre $0,4 \mathrm{e} 10 \mathrm{cpg}$.

Outra abordagem não invasiva que propõe investigar a participação das via M e P em estudos de discriminação do contraste acromático foi feita por Joel Pokorny e Vivian Smith na Universidade de Chicago. Eles desenvolveram três paradigmas que se baseiam na inclinação de uma função de limiares de discriminação de contrastes acromáticos. Os paradigmas são chamados de: pedestal pulsado, pedestal constante e pedestal-delta-pedestal (Pokorny; Smith, 1997). A ideia básica do desenho experimental é a presença de um arranjo de quatro quadrados (pedestal) sobre um fundo de luminância homogênea. No paradigma do pedestal pulsado, esse arranjo é mostrado por um tempo específico e depois desaparece. Um dos quadrados do arranjo é mostrado com luminância diferente (maior ou menor) dos demais. A tarefa é identificar o quadrado diferente. A cada acerto na identificação, a diferença de luminância entre o quadrado teste e os demais é diminuída com o intuito de estimar o contraste limiar de discriminação. Segundo os autores esse paradigma expressa a atividade da via P. No paradigma do pedestal constante, o arranjo de quadrados é constante na tela e apenas um dos quadrados muda de luminância em relação aos demais. A tarefa é identificar o quadrado que mudou de luminância. Aqui também é buscado 
o limiar de discriminação do contraste acromático. Segundo os autores esse protocolo permite a estimativa da atividade da via $\mathrm{M}$. O paradigma pedestal-delta-pedestal é semelhante ao teste do pedestal constante; no entanto, durante o período de mudança do estímulo todo o arranjo aumenta ou diminui de luminância em relação ao fundo, e um dos quatro tem uma mudança diferente dos demais quadrados do arranjo. Segundo os autores, esse protocolo também representa a atividade da via $\mathrm{M}$.

Leonova et al. (2003) adaptaram o paradigma dos pedestais pulsado e constante para a apresentação de estímulos com contraste acromático em diferentes frequências espaciais. O procedimento consistia em mostrar o pedestal e numa das posições do pedestal era colocado um estímulo com contraste espacial periódico. O teste foi realizado com o intuito de estimar o contraste limiar do sujeito para aquela determinada frequência espacial. $\mathrm{O}$ teste foi realizado em diferentes luminâncias médias em cada frequência espacial. Os autores encontraram que para o paradigma do pedestal pulsado a função de sensibilidade ao contraste mostrava um perfil passa-banda e que para o paradigma do pedestal constante a função de sensibilidade ao contraste mostrava um perfil passa-baixa. Os autores sugeriram que a função com perfil passa-banda refletia a atividade da via $\mathrm{P}$ e que as frequências espaciais baixas da função passa-baixa refletia a atividade da via $M$.

\section{Aplicação clínica da função de sensibilidade ao contraste espacial de luminância}

Visto que a função de sensibilidade ao contraste espacial de luminância representa a atividade de vários canais corticais seletivos a bandas de frequências espaciais e que eles podem representar pelo menos parcialmente a atividade das vias paralelas retino-genículo-estriadas $\mathrm{M}$ e $\mathrm{P}$, muitos trabalhos têm buscado investigá-la com intuito de avaliar a visão espacial em condições mórbidas e avaliar se há um comprometimento funcional prioritário de algum dos canais de processamento espacial. A função de sensibilidade ao contraste espacial de luminância já foi utilizada como método investigativo da função visual em estudos com pacientes que sofrem de doenças degenerativas como glaucoma (Motolko; Phelps, 1984), catarata (Drews-Bankiewicz et al., 1992), ambliopia (Volkers et al., 1987), diabetes (Sokol et al., 1985; Liska; Dostálek, 1999), esclerose múltipla (Kupersmith et al., 1984) e acidente vascular encefálico (Dos Santos; Andrade, 2012); doenças infeciosas como hanseníase (Daniel et al., 2005) e tuberculose (Woung et al., 1995); doenças neurotóxicas como intoxicação por solventes orgânicos (Lacerda et al., 2012), mercúrio (Rodrigues et al., 2007) e álcool etílico (Castro et al., 2009); e desnutrição (Dos Santos et al., 2009).

O uso da avaliação da função de sensibilidade ao contraste espacial de luminância como uma ferramenta para o estudo das disfunções visuais é um bom exemplo de como pesquisas inicialmente motivadas pelo desejo de compreender como funciona o organismo humano pode encontrar um nicho importante em 
aplicações médicas. Além disso, esse tipo de conhecimento tem sido usado na indústria para orientar o desenho de equipamentos ópticos e optoeletrônicos como a televisão de alta resolução espacial e temporal (Televisão Ultra HD) testada recentemente no Carnaval do Rio de Janeiro de 2013 pela empresa japonesa Nippon Hõsõs Kyõskai (NHK, 2013).

\section{Referências}

BARLOW, H. B. et al. Retinal ganglion cells responding selectively to direction and speed of image motion in the rabbit. Journal of Physiology, London, v.173, p.377-407, 1964.

BLAKEMORE, C.; CAMPBELL, F. W. Adaptation to spatial stimuli. Journal of Physiology, London, v.200, p.11P-13P, 1969a.

On the existence of neurones in the human visual system selectively sensitive to the orientation and size of retinal images. Journal of Physiology, London, 203, 237 $60,1969 b$.

BLAKEMORE, C. et al. Lateral inhibition between orientation detectors in the human visual system. Nature, v.228, p.37-9, 1970.

BLASDEL, G. G.; LUND, J. S. Termination of afferent axons in macaque striate cortex. Journal of Neuroscience, v.3, p.1389-413, 1983.

CAMPBELL, F. W.; GREEN, D. C. Optical and retinal factors affecting visual resolution. Journal of Physiology, London, v.181, p.576-93, 1965.

CAMPBELL, F. W. GUBISCH, R. W. Optical quality of the human eye. Journal of Physiology, London, v.186, p.558-78, 1966.

CAMPBELL, F. W.; KULIKOWSKI, J. J. Orientational selectivity of the human visual system. Journal of Physiology, London, v.187, p.437-45, 1966.

Electrophysiological measure of the psychophysical contrast threshold. Journal of Physiology, London, v.217, p.54P-55P, 1971.

. Visual evoked potential as a function of contrast of a grating pattern. Journal of Physiology, London, v.222, p.345-56, 1972.

CAMPBELL, F. W.; MAFFEI, L. Electrophysiological evidence for the existence of orientation and size detectors in the human visual system. Journal of Physiology, London, v.207, p.635-52, 1970.

CAMPBELL, F. W.; ROBSON, J. G. Application of Fourier analysis to the visibility of gratings. Journal of Physiology, London, v.197, p.551-66, 1968.

CASTRO, A. J. O. et al. Impairment of color spatial vision in chronic alcoholism measured by psychophysical methods. Psychology \& Neuroscience, v.2, p.179-87, 2009.

CHATTERJEE, S.; CALLAWAY, E. M. Parallel colour-opponent pathways to primary visual cortex. Nature, v.426, p.668-71, 2003.

CRONER, L. J.; KAPLAN, E. Receptive fields of P and M ganglion cells across the primate retina. Vision Research, v.35, p.7-24, 1995. 
DACEY, D. M. et al. Fireworks in the primate retina: in vitro photodynamics reveals diverse LGN-projecting ganglion cell types. Neuron, v.37, p.15-27, 2003.

DACEY, D. M.; LEE, B. B. The "blue-on" opponent pathway in primate retina originates from a distinct bistratified ganglion cell type. Nature, v.367, p.731-5, 1994.

DACEY, D. M.; PACKER, O. S. Colour coding in the primate retina: diverse cell types and cone-specific circuitry. Current Opinion in Neurobiology, v.13, p.421-7, 2003.

DANIEL, E. et al. Impaired contrast sensitivity among leprosy patients with normal visual acuity. Leprosy Reviews, v.76, p.55-64, 2005.

DeVRIES, S. H. Bipolar cells use kainate and AMPA receptors to filter visual information into separate channels. Neuron, v.28, p.847-56, 2000.

DeVRIES, S. H.; SCHWARTZ, E. A. Kainate receptors mediate synaptic transmission between cones and off' bipolar cells in a mammalian retina. Nature, v.397, p.157-60, 1999.

DOS SANTOS, N. A.; ANDRADE, S. M. Visual contrast sensitivity in patients with impairment of functional independence after stroke. BMC Neurology, v.12, p.90, 2012.

DOS SANTOS, N. A. et al. Contrast sensitivity function of sine-wave gratings in children with acute malnutrition. Psychology \& Neuroscience, v.1, p.11-15, 2009.

DREWS-BANKIEWICZ, M. A. et al. Contrast sensitivity in patients with nuclear cataracts. Archives in Ophthalmology, v.110, p.953-9, 1992.

GILINSKY, A. S. Orientation-specific effects of patterns of adapting light on visual acuity. Journal of the Optical Society of America, v.58, p.13-18, 1968.

HENDRICKSON, A. E. et al. The neuroanatomical organization of pathways between the dorsal lateral geniculate nucleus and visual cortex in old world and new world monkeys. Journal of Comparative Neurology, v.182, p.123-36, 1978.

IRVIN, G. E. et al. Center/surround relationships of magnocellular, parvocellular, and koniocellular relay cells in primate lateral geniculate nucleus. Visual Neuroscience, v.10, p.363-73, 1993.

KAPLAN, E.; SHAPLEY, R. M. The primate retina contains two types of ganglion cells, with high and low contrast sensitivity. Proceedings of the National Academy of Science of the USA, v.83, p.2755-7, 1986.

KUFFLER, S. W. Discharge patterns and functional organization of mammalian retina. Journal of Neurophysiology, v.16, p.37-68, 1953.

KUPERSMITH, M. J. et al. Contrast sensitivity loss in multiple sclerosis: selectivity by eye, orientation, and spatial frequency measured with the evoked potential. Investigative Ophthalmology and Visual Science, v.25, p.632-9, 1984.

LACERDA, E. M. C. B. et al. Psychophysical evaluation of achromatic and chromatic vision of workers chronically exposed to organic solvents. Journal of Environmental and Public Health, doi: 10.1155/2012/784390, 2012.

LACHICA, E. A. et al. Parallel pathways in macaque monkey striate cortex: anatomically defined columns in layer III. Proccedings of the National Academy of Science of the USA, v.89, p.3566-70, 1992.

LAMB, T. D.; PUGH JUNIOR, E. N. A quantitative account of the activation steps 
involved in phototransduction in amphibian photoreceptors. Journal of Physiology, London, v.449, p.719-58, 1992.

LAMB, T. D.; PUGH JUNIOR, E. N.Phototransduction, dark adaptation, and rhodopsin regeneration. Investigative Ophthalmology and Visual Science, v.47, p.5138-52, 2006.

LEE, B. B. et al. Amplitude and phase of responses of macaque retinal ganglion cells to flickering stimuli. Journal of Physiology, London, v.414, p.245-63, 1989a.

Sensitivity of macaque retinal ganglion cells to chromatic and luminance flicker. Journal of Physiology, London, v.414, p.223-43, $1989 \mathrm{~b}$.

. Nonlinear summation of M- and L-cone inputs to phasic retinal ganglion cells of the macaque. Journal of Neuroscience, v.9, p.1433-42, 1989c.

Visual responses of ganglion cells of a New World primate, the capuchin monkey, Cebus apella. Journal of Physiology, London, v.528.3, p.573-90, 2000.

LEONOVA, A. et al. Spatial frequency processing in inferred PC-and MC-pathways. Vision Research, v.43, p.2133-9, 2003.

LISKA, V.; DOSTÁLEK, M. Are contrast sensitivity functions impaired in insulin dependent diabetics without diabetic retinopathy? Acta Medica, v.42, p.133-8, 1999.

LUO, Y. R. Why is the human visual system sensitive only to light of wavelengths from approximately 760 to $380 \mathrm{~nm}$ ? An answer from thermochemistry and chemical kinetics. Biophysical Chemistry, v.83, p.179-84, 1999.

MANGEL, S. C.; MILLER, R. F. Horizontal cells contribute to the receptive field surround of ganglion cells in the rabbit retina. Brain Research, v.414, p.182-6, 1987.

MASLAND, R. H. Fundamental plan of the retina. Nature Neuroscience, v.4, p.877-86, 2001 .

MOTOLKO, M. A.; PHELPS, C. D. Contrast sensitivity in asymmetric glaucoma. International Ophthalmology, v.7, p.45-9, 1984.

NAKA, K. I.; RUSHTON, W. A. H. S-potentials from colour units in the retina of fish (Cyprinidae). Journal of Physiology, London, v.185, p.536-55, 1966.

NAKAYAMA, K.; MACKEBEN, M. Steady state visual evoked potentials in the alert primate. Vision Research, v.22, p.1261-71, 1982.

NAWY, S.; JAHR, C. E. Suppression by g lutamate of cGMP-activated conductance in retinal bipolar cells. Nature, v.346, p.269-71, 1990.

. cGMP-gated conductance in retinal bipolar cells is suppressed by the photoreceptor transmitter. Neuron, v.7, p.677-83, 1991.

NHK. Globo e NHK iniciam teste com nova tecnologia de televisão ultra HD. Disponível em: <http://gl.globo.com/rio-de-janeiro/carnaval/2013/noticia/2013/02/ globo-e-nhk-iniciam-teste-com-nova-tecnologia-de-televisao-ultra-hd.html>. 2013.

ODOM, J. V. et al. Visual evoked potentials standard (2004). Documenta Ophthalmologica, v.108, p.115-23, 2004.

PANTLE A. S.; SEKULER, R. W. Six detecting mechanisms in human vision. Science, v.162, p.1146-8, 1968. 
PERRY, V. H. et al. Retinal ganglion cells that project to the dorsal lateral geniculate nucleus in the macaque monkey. Neuroscience, v.12, p.1101-23, 1984.

POKORNY, J.; SMITH, V. C. Psychophysical signatures associated with magnocellular and parvocellular pathway contrast gain. Journal of the Optical Society of America A, v.14, p.2477-86, 1997.

REGAN, D. Human perception of objects: early visual processing of spatial form defined by luminance, color, texture, motion, and binocular disparity. Sunderland, MA, USA: Sinauer Associates, 2000.

RODRIGUES, A. R. et al. Mercury toxicity in the Amazon: contrast sensitivity and color discrimination of subjects exposed to mercury. Brazilian Journal of Medical and Biological Research, v.40, p.415-24, 2007.

RUDVIN, I. et al. Visual evoked potentials and magnocellular and parvocellular segregation. Visual Neuroscience, v.17, p.579-90, 2000.

SCHADE, O. H. Optical and photoelectric analog of the eye. Journal of Optical Society of America, v.46, p.721-39, 1956.

SILVEIRA, L. C. L.; PERRY, V. H. The topography of magnocellular projecting ganglion cells (M-ganglion cells) in the primate retina. Neuroscience, v.40, p.217-37, 1991.

SILVEIRA, L. C. L. et al. Ganglion cells of a short wavelength sensitive cone pathway in New World monkeys: morphology and physiology. Visual Neuroscience, v.16, p.333$43,1999$.

SOKOL, S. et al. Contrast sensitivity in diabetics with and without background retinopathy. Archives in Ophthalmology, v.103, p.51-4, 1985.

SOUZA, G. S. et al. Spatial luminance contrast sensitivity measured with transient VEP: comparison with psychophysics and evidence for multiple mechanisms. Investigative Ophthalmology \& Visual Science, v.48, p.3396-404, 2007.

Amplitude of the transient visual evoked potential (tVEP) as a function of achromatic and chromatic contrast: contribution of different visual pathways. Visual Neuroscience, v.25, p.317-25, 2008.

Comparative neurophysiology of spatial luminance contrast sensitivity. Psychology \& Neuroscience, v.4, p.29-48, 2011.

Contrast processing mechanisms in human visual cortex assessed by visual evoked potentials. Journal of Medicine and Medical Sciences, v.3, p.831-7, 2012.

SZMAJDA, B. A. et al. Retinal ganglion cell inputs to the koniocellular pathway. Journal of Comparative Neurology, v.510, p.251-68, 2008.

UNGERLEIDER, L. G.; MISHKIN, M. Two cortical visual systems. In: INGLE, D. J. et al. (Ed.) The analysis of visual behavior. Cambridge, MA, USA: MIT Press, 1982 . p.549-86.

VALBERG, A.; RUDVIN, I. Possible contributions of magnocellular- and parvocellular- pathway cells to transient VEPs. Visual Neuroscience, v.14, p.1-11, 1997.

VAN ESSEN, D. C. et al. Information processing in the primate visual system: an integrated systems perspective. Science, v.255, p.419-23, 1992.

VOLKERS, A. C. et al. Spatial contrast sensitivity and the diagnosis of amblyopia. British Journal of Ophthalmology, v.71, p.58-65, 1987. 
WERBLIN, F. S.; DOWLING, J. E. Organization of the retina of the mudpuppy, Necturus maculosus. II. Intracellular recording. Journal of Neurophysiology, v.32, p.339-55, 1969.

WOUNG, L. C. et al. Visual function in recovered ethambutol optic neuropathy. Journal of Ocular Pharmacology, v.11, p.411-19, 1995.

YABUTA, N. H.; CALLAWAY, E. M. Functional streams and local connections of layer $4 \mathrm{C}$ neurons in primary visual cortex of the macaque monkey. Journal of Neuroscience, v.18, p.9489-99, 1998.

YAU, K. W. Phototransduction mechanisms in retinal rods and cones. Investigative Ophthalmology \& Visual Science, v.35, p.9-32, 1994.

ZHANG, A. J.; WU, S. M. Receptive fields of retinal bipolar cells are mediated by heterogeneous synaptic circuitry. Journal of Neuroscience, v.21, p.789-97, 2009.

RESUMO - O primeiro estágio de processamento da informação do estímulo visual consiste na contagem de fótons pelas células fotorreceptoras. Nos estágios pós-receptorais a informação de intensidade absoluta do estímulo é transformada em comparações de informações provindas de áreas adjacentes da retina e momentos sucessivos. Essa métrica implementada pelo sistema visual para quantificar o estímulo é chamada de contraste - contraste espacial ou simultâneo e contraste temporal ou sucessivo. A presença de contraste é essencial para a geração de percepção visual consciente no domínio do espaço e do tempo e em três dimensões ortogonais de cores - branca e preta; azul e amarela; verde e vermelha. Uma curva em forma de sinodelimita os limiares de detecção de contraste em função da frequência especial ou temporal do estímulo. Ela é chamada função de sensibilidade ao contraste e é afetada por uma série de fatores ópticos e neurais. Neurônios de diferentes classes contribuem para regiões diferentes da função de sensibilidade ao contraste e suas atividades representam as ações de vias de processamento visual que se estendem da retina ao córtex visual. Investigações básicas e clínicas têm dado suporte à importância do estudo da sensibilidade ao contraste espacial de luminância (branco e preta) como uma ferramenta indicadora da função visual em sujeitos normais e afetados por disfunções neuro-oftalmológicas.

PALAVRAS-CHAVE: Sensibilidade ao contraste, Visão espacial, Visão temporal, Processamento paralelo visual.

ABSTRACT - The first step in the information processing of visual stimuli corresponds to foton counting by photorreceptor cells. In the post-receptoral steps, information on the stimulus absolute intensity is converted in comparisons between information coming from adjacent retinal areas or successive moments. This metrics implemented by the visual system to quantify the stimulus is called contrast - spatial or simultaneous contrast and temporal or successive contrast. Contrast is essential to the generation of conscious visual perception in the domain of space and time and in three orthogonal color dimensions - black and white, blue and yellow, and green and red. A Bell-shaped curve delimits the thresholds of contrast detection as a function of spatial or temporal frequency. It is called contrast sensitivity function and is affected by several optical and neural factors. Different classes of neurons contribute to different regions of the contrast sensitivity function and their activities represent the work of visual processing 
pathways that begin in the retina and end in the visual cortex. Basic and clinical investigations have given support to the importance of the study of luminance (black and white) spatial contrast sensitivity as a tool to evaluate the visual function in normal and subjects affected by neuro-ophthalmologic dysfunctions.

KErWORDS: Contrast sensitivity, Spatial vision, Temporal vision, Visual parallel processing.

Givago da Silva Souza é doutor pela Universidade Federal do Pará (UFPA).

@-givagosouza@ufpa.br

Eliza Maria da Costa Brito Lacerda é mestre em Neurociência pela Universidade Fe-deral do Pará (UFPA). @ - eliza_lacerda@yahoo.com.br

Vladimir de Aquino Silveira é bacharel em Física pela Universidade Federal do Pará (UFPA). @-silveirava@gmail.com

Carolina dos Santos Araújo é licenciada em Ciências Biológicas pela Universidade Federal do Pará (UFPA). @-carolinacdsa@gmail.com

Luiz Carlos de Lima Silveira é doutor pela Universidade Federal do Pará (UFPA). @- luiz@ufpa.br

Agradecimentos: Este trabalho recebeu suporte financeiro dos seguintes projetos: CNPq-Pronex/ Fapespa \#316799/2009; CNPq \#475860/2010-1 e \#486545/2012-1; Finep/ UFPA/Fadesp \#1723 (IBN Net). EMCBL recebeu bolsa de doutorado Capes-PROF. VAS recebeu bolsa de mestrado CNPq. CSA recebeu bolsa de mestrado Capes-PROF. LCLS recebeu bolsa de produtividade científica do CNPq.

Recebido em 18.2.2013 e aceito em 28.2.2013. 